Rev. Bras. Saúde Prod. Anim., Salvador, v.13, n.2, p.306-317 abr./jun., 2012 http://www.rbspa.ufba.br ISSN 15199940

\title{
Produção de forragem de Tifton 85 adubado com nitrogênio e submetido à lotação contínua ${ }^{1}$
}

\author{
Forage production of Tifton 85 fertilized with nitrogen and subjected to continuous \\ stocking
}

\author{
FAGUNDES, Jailson Lara ${ }^{2}$, MOREIRA, Andréia Luciane ${ }^{3}$, FREITAS, Acyr Wanderley \\ de Paula ${ }^{3}$, ZONTA, Augusto ${ }^{3}$, HENRICHS, Reges ${ }^{4}$, ROCHA, Fernanda Cipriano ${ }^{5}$ \\ ${ }^{1}$ Pesquisa financiada pela Fundação de Amparo à Pesquisa do Estado de São Paulo. \\ ${ }^{2}$ Universidade Federal do Sergipe, Departamento de Zootecnia, São Cristovão, Sergipe, Brasil. \\ ${ }^{3}$ Agência Paulista de Tecnologia dos Agronegócios, Departamento de Descentralização do Desenvolvimento, \\ Campinas, São Paulo, Brasil. \\ ${ }^{4}$ Universidade Estadual Paulista, Departamento de Zootecnia, Dracena, São Paulo, Brasil. \\ ${ }^{5}$ Universidade Federal Fluminense, Faculdade de Veterinária, Niterói, Rio de Janeiro, Brasil. \\ *Endereço para correspondência: aluciane@apta.sp.gov.br
}

\section{RESUMO}

O presente estudo foi realizado na Unidade de Pesquisa e Desenvolvimento de Adamantina/SP, da Agência Paulista de Tecnologia dos Agronegócios (APTA) - Pólo da Alta Paulista, com o objetivo de avaliar o efeito da adubação nitrogenada na composição morfológica, densidade populacional de perfilhos, índice de área foliar, interceptação luminosa e acúmulo de forragem em pastos de Tifton 85 submetidos ao regime de lotação contínua. Os tratamentos corresponderam a quatro doses de Nitrogênio $(0 ; 100 ; 200$ e $400 \mathrm{~kg} / \mathrm{ha} /$ ano de $\mathrm{N})$, dispostos em delineamento experimental de blocos casualizados, com quatro repetições. Os pastos de Cynodon cv. Tifton 85 estudados sofreram influência da época de avaliação e das doses de nitrogênio com efeito marcante na composição morfológica, índice de área foliar, interceptação luminosa e densidade populacional de perfilhos, que foram determinantes no acúmulo de forragem. Foi constatado efeito linear positivo da adubação nitrogenada na densidade de perfilhos vegetativos, perfilhos totais e acúmulo de forragem. A adubação nitrogenada teve efeito marcante na quantidade de perfilhos totais e vegetativos, no índice de área foliar, interceptação luminosa e acúmulo de forragem. $\mathrm{O}$ cultivar Tifton 85 não atingiu as condições necessárias para a taxa de crescimento da cultura máxima, quando manejado sob lotação contínua, em virtude do pasto ser mantido a $10 \mathrm{~cm}$ de altura.

Palavras-chave: características estruturais, Cynodon spp., ovinos, pastejo

\section{SUMMARY}

The present assay was conducted at the Research and Development of Adamantina, SP, of the Agência Paulista de Tecnologia dos Agronegócios (APTA) - Pólo da Alta Paulista to evaluate the effect of nitrogen fertilization on morphological composition, density of tillers, leaf area index, light interception and herbage accumulation in grazed Tifton 85 subjected to continuous stocking system. The treatments consisted of four levels of nitrogen $(0 ; 100 ; 200$ and $400 \mathrm{~kg} / \mathrm{ha} /$ year of $\mathrm{N}$ ), arranged in a randomized complete blocks experimental design with four replications. The grasslands of Cynodon cv. Tifton 85 studied influenced the time of evaluation and of nitrogen levels with a marked effect in morphological composition of the pasture, leaf area index, light interception and population density of tillers that were instrumental in the accumulation of forage. It was found a positive linear effect of nitrogen fertilization on the density of vegetative tillers, totals and herbage accumulation nitrogen fertilization had a marked effect on the amount of total and vegetative tillers, leaf area index in light interception and herbage accumulation. The cultivar Tifton 85 has not reached the necessary conditions for crop growth rate maximum when managed under continuous stocking keeping the grass to $10 \mathrm{~cm}$ tall.

Keywords: Cynodon spp., grazing, ovine, structural characteristics 


\section{INTRODUÇÃO}

Dentre as gramíneas forrageiras utilizadas para alimentação animal e, altamente responsivas à adubação nitrogenada, os cultivares de Cynodon têm se destacado por apresentarem elevada produção de massa seca, alto valor nutritivo, alta capacidade de suporte de animais, e, sendo assim, são recomendadas para sistemas de produção ovina (CARNEVALLI et al., 2001; ESTRADA et al., 2003; PACIULLO et al., 2005).

Práticas como calagem, manejo do pastejo, irrigação e adubação de pastagens, particularmente, a nitrogenada proporcionam aumentos em produção de matéria. Dessa forma, a utilização da fertilização nitrogenada tem proporcionado mudanças na produção de forragem devido alterações que ocorrem nas características morfológicas e estruturais das plantas forrageiras, influenciando o comprimento final das folhas, alongamento foliar, densidade populacional de perfilhos, índice de área foliar e composição morfológica, que reflete na produção de matéria seca (FAGUNDES et al., 2006a; FAGUNDES et al., 2006b). Vários trabalhos reportam aumento da produtividade com a utilização de adubação nitrogenada, com efeito marcante na densidade populacional de perfilhos, alongamento e aparecimento foliar influenciando na produção de matéria seca (ALEXANDRINO et al., 2004; BARBERO et al., 2009).

A produção forrageira, como resultado dos processos de crescimento e desenvolvimento pode ter sua eficiência modificada pela utilização de práticas que influenciam a morfogênese das forrageiras. Nesse contexto, a manipulação das características estruturais do pasto, tais como: altura do dossel, índice de área foliar, densidade populacional de perfilhos, densidade da biomassa vegetal, entre outras, podem explicar as respostas tanto de plantas, quanto de animais de maneira consistente (FAGUNDES et al., 2001; GOMIDE et al., 2003; ANDRADE et al., 2006).

A altura do pastejo é uma característica que possui relação direta com os aspectos morfológicos e fisiológicos da planta nos componentes estruturais das mesmas, na produção e qualidade da forragem produzida. Nesse sentido, a altura do pasto permite estabelecer guias de manejo de pastagem, dada a sua facilidade de compreensão, análise e aplicação (CARNEVALLI \& SILVA, 1999; GOMIDE et al., 2003).

Conduziu-se este trabalho com o objetivo de avaliar o efeito da adubação nitrogenada na composição morfológica, densidade populacional de perfilhos, índice de área foliar, interceptação luminosa e acúmulo de forragem em pastos de Tifton 85 submetidos ao regime de lotação contínua.

\section{MATERIAL E MÉTODOS}

O trabalho foi conduzido no Pólo da Alta Paulista, da Agência Paulista de Tecnologia dos Agronegócios (APTA), Secretaria da Agricultura. A área experimental está situada sob as coordenadas geográficas aproximadas de $21^{\circ} 40^{\prime} \mathrm{S}$ de latitude, $51^{\circ} 08^{\prime} \mathrm{W}$ de longitude e 415 metros de altitude. $\mathrm{O}$ clima da região é do tipo Cwa, com estação chuvosa, quente no verão e inverno seco. Os dados de precipitação e temperaturas durante $o$ período experimental estão apresentados na Tabela 1. O experimento foi instalado em solo classificado como argissolo vermelho-amarelo, eutrófico, moderado, textura arenosa/média e topografia ondulada, cuja análise revelou os 
seguinte resultados: $\mathrm{pH}\left(\mathrm{CaCl}_{2}\right)=5,2$; $\mathrm{MO}(\mathrm{g} / \mathrm{kg})=11,0 ; \mathrm{P}\left(\mathrm{MG} / \mathrm{dm}^{3}\right)=16,0 ;$ $\mathrm{K}\left(\mathrm{cmol}_{\mathrm{c}}\right)=2,3 ; \mathrm{Ca}\left(\mathrm{cmol}_{\mathrm{c}}\right)=16,0 ; \mathrm{Mg}$ $\left(\mathrm{cmol}_{\mathrm{c}}\right)=8,0 ; \mathrm{H}+\mathrm{Al}\left(\mathrm{cmol}_{\mathrm{c}}\right)=15,0 ; \mathrm{SB}$ $\left(\mathrm{cmol}_{\mathrm{c}}\right)=24,5 ; \mathrm{T}\left(\mathrm{cmol}_{\mathrm{c}}\right)=41,0$ e V $(\%)$ $=63,0$.

Em decorrência dos resultados da análise de solo, realizou-se a adubação e calagem. A calagem foi realizada de forma a elevar a saturação de bases a
$70 \%$ (01/03/2007), e a adubação de base foi constituída de 150kg/ha na formulação 3-36-18 (NPK), aplicados no sulco de plantio $(06 / 11 / 2007)$. Em 28/12/2007, procedeu-se roçada para uniformização da altura do relvado a $10 \mathrm{~cm}$. No dia 02/01/2008, iniciou-se o período de adaptação dos ovinos à rotina do experimento e da alimentação.

Tabela 1. Precipitação pluviométrica e temperaturas mensais do ar (máxima, mínima e média) durante o período experimental

\begin{tabular}{lccccc}
\hline \multirow{2}{*}{ Mês } & Umidade Relativa & Precipitação & \multicolumn{3}{c}{ Temperatura $\left({ }^{\circ} \mathrm{C}\right)$} \\
\cline { 4 - 6 } & do ar $(\%)$ & $(\mathrm{mm})$ & Máxima & Mínima & Média \\
\hline Novembro/07 & 82,7 & 141,8 & 31,4 & 19,3 & 25,3 \\
Dezembro/07 & 82,4 & 52,2 & 32,7 & 20,6 & 26,7 \\
Janeiro/08 & 86,7 & 134,6 & 30,5 & 21,0 & 30,5 \\
Fevereiro/08 & 87,5 & 150,4 & 31,0 & 20,3 & 25,7 \\
Março/08 & 82,1 & 87,4 & 30,4 & 19,0 & 24,7 \\
Abril/08 & 81,6 & 126,0 & 29,6 & 18,1 & 23,8 \\
Maio/08 & 78,8 & 59,1 & 26,1 & 13,2 & 19,6 \\
\hline
\end{tabular}

Fonte: Posto Meteorológico da APTA - Pólo da Alta Paulista (2008), localizado a 500m do experimento.

Os tratamentos consistiram de quatro doses de nitrogênio, controle ou $0 ; 100$; 200 e $400 \mathrm{~kg} / \mathrm{ha} / \mathrm{ano}$. Utilizou-se a ureia como fonte de adubo nitrogenado, distribuído nas unidades experimentais em três aplicações, 15/01, 16/02 e 10/03/2008. O delineamento experimental utilizado foi o de blocos casualizados com parcelas subdivididas, estudados os tratamentos nas parcelas e épocas nas subparcelas, com quatro repetições.

As unidades experimentais consistiram de 16 piquetes com áreas que variavam de 300 a $500 \mathrm{~m}^{2}$, inversamente à dose de $\mathrm{N}$ aplicada, de modo a permitir a manutenção de taxa de lotação mais uniforme em todos os piquetes. Foram utilizados ovinos da raça Santa Inês como animais "testes", e animais mestiços da raça Santa Inês como "reguladores de carga animal". Os animais foram pareados em função do peso vivo e alocados (dois a dois) como unidades experimentais, a partir de 01/01/2008.

$\mathrm{O}$ pasto foi manejado sob lotação contínua, com taxa de lotação variável. A altura média do pasto foi mantida em torno de $10 \mathrm{~cm}$, pela adição ou retirada dos animais reguladores. Estes foram inseridos ou removidos dos piquetes, de acordo com a necessidade de manter a altura do pasto relativamente estável a $10 \mathrm{~cm}$. A altura do pasto foi monitorada, semanalmente, por meio de 40 medidas, realizadas ao acaso em cada piquete utilizando-se uma régua com divisões de $1 \mathrm{~cm}$.

Para avaliação da composição morfológica do pasto foram colhidas três amostras de forragem ao nível do solo, 
em um quadro amostral com $0,16 \mathrm{~m}^{2}$ $(40 \mathrm{x} 40 \mathrm{~cm})$ por unidade experimental em cada amostragem, as quais foram coletadas em áreas representativas das parcelas experimentais. Estas amostras de forragem colhidas foram sub-amostradas e fracionadas em folhas (lâminas foliares verdes), colmos verdes (colmo + bainha foliar) e material morto (perfilhos e folhas mortas), pesadas e secas em estufa de circulação e renovação forçada de ar, a $65^{\circ} \mathrm{C}$, e, posteriormente, pesadas. A partir da participação dos componentes folha, colmo e material morto na massa seca total de cada amostra colhida foi estimada a massa de cada um dos componentes no dossel forrageiro.

$\mathrm{Na}$ avaliação da densidade populacional de perfilhos, utilizou-se um anel de cano plástico (PVC) de $15 \mathrm{~cm}$ de diâmetro $\left(0,0165 \mathrm{~m}^{2}\right)$, fixado ao solo e , em cada unidade experimental, existiam dois anéis. Fixado o anel, procedeu-se a contagem do número total de perfilhos basilares, vegetativos e mortos. Já para se obter o número de perfilhos totais, realizou-se a soma dos perfilhos vegetativos e mortos.

As avaliações de interceptação luminosa (IL) e do índice de área foliar (IAF) do relvado foram medidas utilizando $\mathrm{o}$ analisador de dossel SUNSCAN: Sistema de Análise da Cobertura Vegetal (Delta T, Cambridge, Inglaterra). Para avaliar o IAF e a IL procedeu-se a medida em 20 pontos escolhidos, de forma aleatória, em cada unidade experimental, dos quais compuseram resultado médio de índice de área foliar e interceptação luminosa.

O acúmulo de forragem foi estimado conforme descrito por Davies (1993). Foram utilizadas três gaiolas de exclusão, por parcela, com área de $1 \mathrm{~m} 2$. As leituras eram realizadas em intervalos de três semanas entre as amostragens, e, posteriormente, eram alocadas em novos pontos representativos do pasto.
Durante o período experimental foram realizadas quatro avaliações: janeiro $(15 / 01$ a 11/02), fevereiro (12/02 a 11/03), março (12/03 a 11/04) e abril (12/04 a 19/05). Os dados foram analisados conforme medidas repetidas no tempo, pelo procedimento MIXED do SAS INSTITUTE (2004). Após a análise de variância resultante do "PROC MIXED", os tratamentos quantitativos, doses de nitrogênio, foram submetidos à análise de regressão mediante $\mathrm{o}$ procedimento PROC REG e os tratamentos qualitativos, época de avaliação, foram submetidos ao teste de Tukey, a 5\% de probabilidade, por meio do procedimento PROC MEANS (SAS INSTITUTE, 2004).

\section{RESULTADOS E DISCUSSÃO}

O manejo dos animais em pastejo foi conduzido de forma criteriosa, o que pode ser constatado pela manutenção da altura do pasto durante o período de janeiro a abril/08, com valores muito próximos da meta estipulada, na fase experimental (Tabela 2).

A adubação nitrogenada não influenciou a porcentagem de colmo e folha do Tifton $85 \quad(\mathrm{P}>0,05)$, os médios apresentados no dossel forrageiro foram de 54 e 28\%, respectivamente, sendo influenciada pela época de avaliação $(\mathrm{P}<0,05)$ - (Tabela 3). Nota-se alteração percentual na composição morfológica dos componentes do pasto com o transcorrer dos meses. Todavia, o pasto foi manejado sob pastejo na altura constante de $10 \mathrm{~cm}$, ocorrendo modificações nos componentes do pasto. Esse fato pode ser explicado pela influência dos fatores climáticos no desenvolvimento dos componentes do Tifton 85, fato bem evidenciado pelos menores valores percentuais de folha, no mês de março, período no qual 
Rev. Bras. Saúde Prod. Anim., Salvador, v.13, n.2, p.306-317 abr./jun., 2012 http://www.rbspa.ufba.br ISSN 15199940

ocorreram as menores precipitações pluviométricas. Resultados similares são relatados por Fagundes et al. (2006a), que ao trabalharem com adubação nitrogenada demonstraram o efeito das condições climáticas nas características morfológicas e estruturais do dossel forrageiro e no desenvolvimento morfológico das plantas.

Tabela 2. Altura do pasto $(\mathrm{cm})$ de Tifton 85 submetidos à adubação nitrogenada e manejados sob lotação contínua

\begin{tabular}{lrccc}
\hline Doses de N (kg/ha) & Janeiro & Fevereiro & Março & Abril \\
\hline 0 & 8,9 & 10,8 & 10,4 & 8,8 \\
100 & 9,6 & 11,7 & 11,8 & 10,8 \\
200 & 10,1 & 11,5 & 11,8 & 10,8 \\
400 & 8,9 & 11,2 & 11,5 & 11,1 \\
\hline Média & 9,4 & 11,3 & 11,4 & 10,4 \\
\hline
\end{tabular}

Tabela 3. Composição morfológica dos pastos (em \%) de Tifton 85 manejados em lotação contínua

\begin{tabular}{llcccc}
\hline Variáveis & Janeiro & Fevereiro & Março & Abril & CV \\
\hline Folha & $32,1^{\mathrm{A}}$ & $27,5^{\mathrm{AB}}$ & $22,9^{\mathrm{B}}$ & $27,9^{\mathrm{AB}}$ & 20,1 \\
Colmo & $56,0^{\mathrm{A}}$ & $61,7^{\mathrm{A}}$ & $60,4^{\mathrm{A}}$ & $43,8^{\mathrm{B}}$ & 18,9 \\
\hline
\end{tabular}

Médias seguidas de mesma letra, na linha, não diferem entre si $(\mathrm{P}>0,05)$.

$\mathrm{CV}=$ Coeficiente de variação

Houve efeito significativo da interação doses de nitrogênio e época de avaliação $(\mathrm{P}<0,05)$ para porcentagem de material morto no dossel, os quais podem ser observados na Figura 1. Observou-se que os dados de porcentagem de material morto ajustaram-se ao modelo linear para o mês de janeiro e quadrático para mês de abril, já nos meses de fevereiro e março não foi constatado efeito da adubação nitrogenada na variável avaliada.

De acordo com os resultados de Carnevalli \& Da Silva (1999), os valores percentuais de folha, para $o$ capim Coastcross, variaram entre 13,7 e $36,9 \%$. Esses autores citam que a quantidade de folhas apresentou valor superior quando os fatores de crescimento não eram limitantes, e houve redução quando ocorreu queda de temperatura e umidade. Essa menor variação pode ser atribuída a curta duração do período de avaliação e ao método de pastejo empregado.

Os valores percentuais de colmo, no pasto, praticamente, tiveram pouca alteração à medida que avançou o período experimental, observado na Tabela 3. Esse comportamento pode ser explicado pela manutenção da altura do pasto em condições similares $(10 \mathrm{~cm})$, ao longo dos meses de janeiro a abril (Tabela 2). No trabalho realizado por Carnevalli \& Silva (1999) com Coastcross submetido à lotação intermitente, os valores percentuais de colmo para o capim Coastcross variaram entre 22,1 e $56,2 \%$.

Os valores médios percentuais de colmo apresentaram variação de 43,8 a $61,7 \%$. 
Se comparado ao trabalho de Carnevalli \& Silva (1999), esses números podem ser considerados inferiores, o que pode ter sido ocasionado aos diferentes métodos de desfolha empregados neste estudo. Cabe comentar que a manutenção da altura do pasto, por meio do manejo de lotação contínua, com carga variável, causa menor alteração na composição morfológica do pasto, comparativamente, à lotação intermitente.

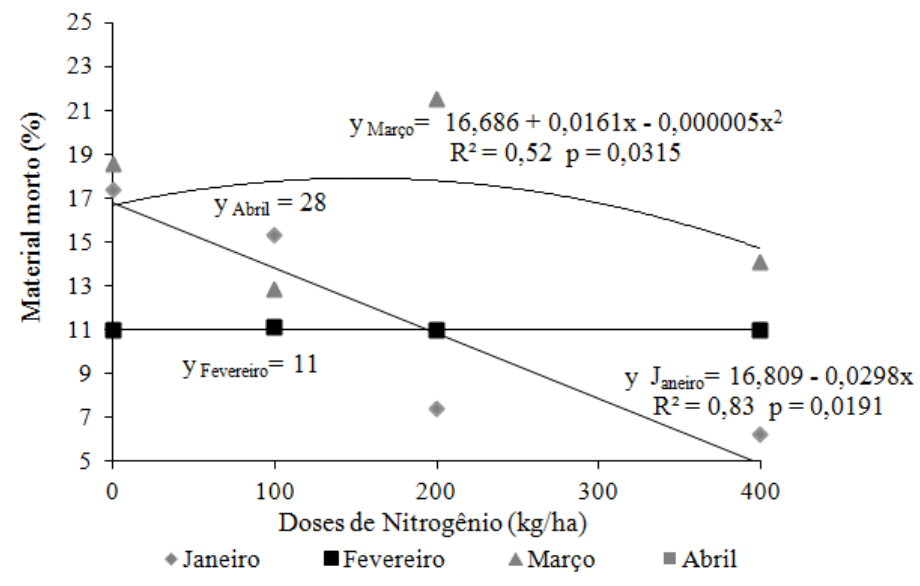

Figura 1. Percentagem de material morto de Tifton 85 submetidos a adubação nitrogenada e manejados sob lotação contínua *Significativo a $5 \%$ pelo teste $\mathrm{F}$

Os valores obtidos para material morto, no pasto, podem ser considerados baixos e poderiam ser indício da alta utilização da forragem produzida. No entanto, uma análise mais cuidadosa dos fatos permite inferir que isso pode não ser verdade, uma vez que a forragem utilizada seria aquela acima da altura de pastejo especificada, e a biomassa mantida abaixo desta, estaria com acesso bastante restrito ao animal. Nesse caso os resultados apontariam apenas para uma mudança na estrutura dos pastos apresentados aos animais.

As variações nas proporções de folha, colmo e material morto, no pasto, são o resultado do equilíbrio dos processos dinâmicos e concomitantes de crescimento e morte/senescência de tecidos, os quais são afetados de forma diferenciada por práticas agronômicas e de manejo.
Não foi constatado efeito da época de avaliação na densidade populacional de perfilhos vegetativos e totais $(\mathrm{P}>0,05)$, já a densidade de perfilhos mortos do Tifton 85 sob pastejo apresentou influência $(\mathrm{P}<0,05)$ da época de avaliação (Tabela 4). Os valores máximos da densidade populacional de perfilhos mortos ocorreram em abril. Provavelmente, a explicação para tal fato deve-se à metodologia de avaliação do perfilhamento utilizada, na qual foram realizados cortes e contagem de perfilhos em épocas distintas e, possivelmente, os perfilhos mortos numa época seriam computados nas épocas seguintes.

A possível explicação para a falta de efeito do período de avaliação na densidade populacional de perfilhos vegetativos e totais seria $o$ fato das comunidades de plantas sob pastejo ajustarem-se às diferentes condições e 
intensidades de desfolha, o que provocaria o efeito de plasticidade (SBRISSIA et al., 2001). Como o presente experimento foi mantido sob mesma intensidade de desfolha, não ocorreram modificações nas respectivas densidade de perfilhos.

Em geral, os valores médios da densidade populacional de perfilhos vegetativos foram de 2590 a 2978 perfilhos $/ \mathrm{m}^{2}$ (Tabela 4), respectivamente, menores que os relatados por Carvalho et al. (2000), para a mesma espécie sob pastejo, que constataram variação de 8620 a 13050 perfilhos $/ \mathrm{m}^{2}$. Essa diferença deve-se ao fato de que os autores computaram todos os perfilhos presentes no pasto (basais e aéreos) e, no presente experimento, foram computados, somente, os perfilhos basais. Foi constatado efeito linear positivo da adubação nitrogenada na densidade de perfilhos vegetativos e totais do Tifton 85 , sob lotação contínua (Figura 2), o que provavelmente decorreu da melhoria do status nutricional das plantas.

Tabela 4. Densidade populacional de perfilhos vegetativos, mortos e totais (perfilho/ $\mathrm{m}^{2}$ ), índice de área foliar, interceptação luminosa e taxa acúmulo de forragem $(\mathrm{kg} / \mathrm{ha} / \mathrm{dia})$ de Tifton 85 submetidos ao pastejo e avaliado em diferentes épocas

\begin{tabular}{lccccc}
\hline Variáveis & Janeiro & Fevereiro & Março & Abril & CV \\
\hline Perfilhos vegetativos & 2978 & 2590 & 2686 & 2797 & 32,2 \\
Perfilhos mortos & $133^{\mathrm{B}}$ & $319^{\mathrm{A}}$ & $239^{\mathrm{AB}}$ & $334^{\mathrm{A}}$ & 35,5 \\
Perfilhos totais & 3111 & 2909 & 2925 & 3131 & 28,1 \\
Índice de área foliar & $2,48^{\mathrm{A}}$ & $2,21^{\mathrm{AB}}$ & $2,46^{\mathrm{A}}$ & $1,98^{\mathrm{B}}$ & 18,4 \\
Interceptação luminosa & $76^{\mathrm{B}}$ & $79^{\mathrm{AB}}$ & $77^{\mathrm{B}}$ & $86^{\mathrm{A}}$ & 8,0 \\
Acúmulo de forragem & $66^{\mathrm{A}}$ & $74^{\mathrm{A}}$ & $51^{\mathrm{B}}$ & $41^{\mathrm{B}}$ & 22,5 \\
\hline
\end{tabular}

Médias seguidas de mesma letra, maiúscula na linha, não diferem entre si $(\mathrm{P}>0,05) \mathrm{CV}$ : Coeficiente de variação

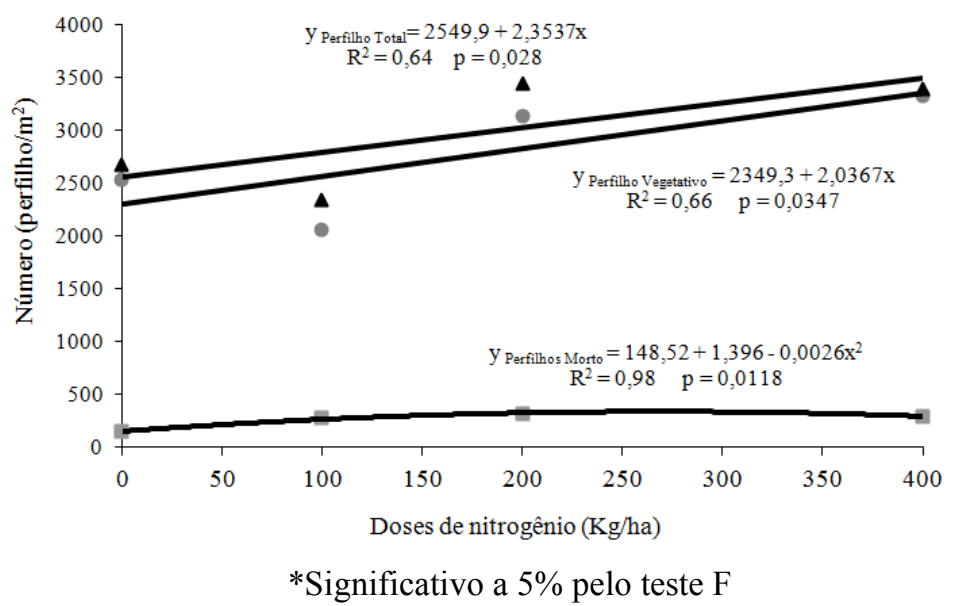

Figura 2. Densidade populacional de perfilhos vegetativos $(\bullet)$, mortos $(\boldsymbol{\Delta})$ e totais $(\boldsymbol{\square})$ de Tifton 85 submetidos a adubação nitrogenada e manejados sob lotação contínua 
A influência do nitrogênio sobre a densidade populacional de perfilhos também foi relatado por Fagundes et al. (2006b) e Morais et al. (2006). Cabe salientar que o efeito da adubação nitrogenada e de estação, ou períodos de avaliação, sobre a população de perfilhos podem ser um dos principais fatores determinante da produção de biomassa, juntamente com o rendimento por perfilho (SBRISSIA et al. 2001; ALENCAR et al., 2010).

Conforme demonstrado por Santos et al. (2009), o aumento na densidade populacional de perfilho é o principal processo pelo qual a produção de forragem é incrementada pela adubação nitrogenada nos pastos sob lotação contínua. Assim, a adoção da técnica de adubação de pastagem com fertilizante nitrogenado pode ser uma importante estratégia para o manejo de pastagem, principalmente, porque aumenta a

(a)

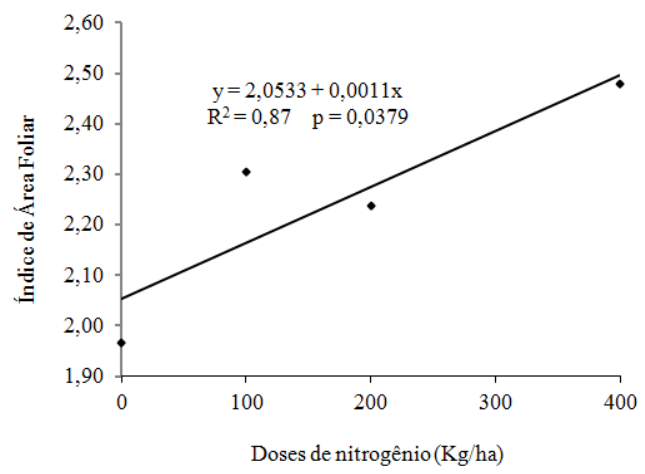

densidade populacional de perfilhos que é determinante da perenidade do pasto.

Não foi constatado efeito significativo da interação doses de nitrogênio e épocas de avaliação para o índice de área foliar (IAF) e interceptação luminosa (IL) (Figura 3 e Tabela 4). Os efeitos ficaram limitados aos fatores isolados de doses de $\mathrm{N}$ e época que mostraram influência significativa $(\mathrm{P}<0,05)$, e de grande magnitude sobre a variável em estudo. O IAF e a IL variaram em função das doses de $\mathrm{N}$ e ajustaram-se ao modelo linear (Figura 3), e da época de avaliação, com menores valores de IAF. Este comportamento ocorreu em abril, devido ao aumento do número de perfilhos mortos (Tabela 4). O aumento do IAF com as doses de $\mathrm{N}$ estão em consonância com os resultados observados por Fagundes et al., (2006a)

*Significativo a $5 \%$ pelo teste $\mathrm{F}$

Figura 3. Índice de área foliar (a) e Interceptação Luminosa (b) de Tifton 85 submetidos à adubação nitrogenada e manejado sob lotação contínua

Verifica-se elevação dos valores de IAF e na IL nos tratamentos que receberam adubação nitrogenada. Possivelmente, isso deve estar relacionado ao fato da melhora no status nutricional das plantas de Tifton 85 ter contribuído para o aumento do número de folhas vivas por perfilhos comprimento final das folhas, taxa de alongamento foliar e densidade populacional de perfilhos, conforme demonstrado por Fagundes et al. (2006a). 
Na ausência da adubação nitrogenada verifica-se que os menores valores de IL (Figura $3 b$ ) podem ser explicados pelos baixos valores de IAF (Figura 3a). Esse efeito pode ocorrer pelo estímulo da emissão de folhas e perfilhos fato decorrente da adubação nitrogenada, processo importante para a restauração da área foliar após corte ou pastejo, o que garante incremento no IAF e IL (FAGUNDES et al., 2006a). Os processos de formação e desenvolvimento de folhas são fundamentais para $o$ crescimento vegetal, dado o papel destas na fotossíntese, ponto de partida para a formação de novos tecidos.

Os valores de IAF variaram entre 1,98 e 2,48 (Tabela 4). É fato amplamente reconhecido que quando $\mathrm{o}$ pasto intercepta $95 \%$ da luz incidente, ter-seia valor de IAF no qual a taxa de crescimento da cultura estaria próxima a um valor máximo. Segundo essa premissa, o cultivar Tifton 85 não preencheu as condições necessárias para atingir a taxa de crescimento máxima da cultura, uma vez que o maior valor de IL encontrado foi de $86 \%$ (Tabela 4). Assim, devido aos fatores ambientais limitantes, associado à manutenção da altura do dossel forrageiro $(10 \mathrm{~cm})$, é provável que não alcançasse a máxima taxa de crescimento cultura do Tifton 85.

Os resultados apontam redução nos valores de IAF à medida que a época de avaliação avançou de janeiro a abril, o que corrobora os resultados de Fagundes et al. (2006a), que relataram diminuições nos valores de IAF, à proporção que as estações do ano avançaram do verãooutono para o inverno-primavera.

A taxa de acúmulo de forragem de Tifton 85 foi influenciada significativamente pela época e adubação nitrogenada $(\mathrm{P}<0,05)$ - (Figura 4). Esse efeito diferencial entre as taxas de acúmulo em relação ao período pode ser atribuído aos fatores climáticos (Tabela 1), que influenciaram as características morfofisiológicas das plantas e alteraram, consequentemente, as taxas de seu crescimento. Nesse contexto, Gomide et al. (2003) destacaram a importância dos fatores ambientais, principalmente temperatura, fotoperíodo e luz, na taxa de aparecimento e alongamento das folhas, para que seja favorecido o IAF e, por conseguinte, o acúmulo de forragem. De fato, convém reiterar que os processos morfofisiológicos são sensíveis às condições climáticas desfavoráveis de disponibilidade de água, temperatura e nutrientes.

De acordo com os resultados de Carnevalli \& Silva (1999), os valores de taxa de acúmulo variaram entre 24,5 e 104,3g/ha/dia de MS e apresentaram padrões semelhantes em diferentes magnitudes aos relatados no presente experimento, com valores entre 40,9 e $73,7 \mathrm{~kg} / \mathrm{ha} /$ dia de MS.

Vale salientar que, no transcorrer dos meses, ocorreu queda nas taxas de acúmulo de forragem. Pode-se constatar que houve influência marcante das condições climáticas e que, possivelmente, tenham ocorrido mudanças nas características morfofisiológicas e na arquitetura do dossel forrageiro. Alterações que podem ser explicadas pela variações dos componentes morfológicos do pasto, densidade populacional de perfilhos, alteração na IL e no IAF relatados no presente estudo.

Quanto ao efeito da adubação nitrogenada no acúmulo de forragem, observou-se que os dados ajustaram-se respectivamente ao modelo linear (Figura 4). Pode-se notar incremento na taxa de acúmulo com a aplicação de nitrogênio, o que indica que o suprimento de $\mathrm{N}$ do solo normalmente não atende à demanda dessa gramínea. Além da escassez de $\mathrm{N}$ no solo, o aumento na densidade populacional de perfilhos, no IAF e na IL, proporcionados 
pela adubação nitrogenada, pode ter influenciado a elevação do acúmulo de massa. Esse incremento em produção de forragem, proporcional às doses de $\mathrm{N}$ em Tifton 85 , seguiu o mesmo padrão de resposta descrita por Fagundes et al. (2005). Esse efeito do $\mathrm{N}$ pode ser atribuído à sua grande influência sobre os processos fisiológicos da planta.

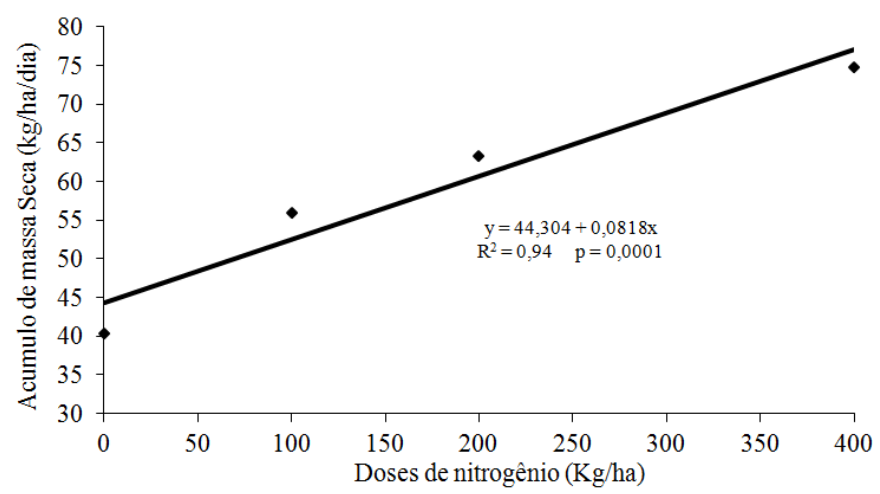

Figura 4. Taxa de acúmulo de forragem de Tifton 85 submetidos a adubação nitrogenada sob lotação contínua *Significativo a $5 \%$ pelo teste $\mathrm{F}$

O efeito diferencial da época de avaliação e das doses de nitrogênio, sobre as taxas de acúmulo do capim-tifton 85 , refletem a ação dos fatores climáticos e da adubação, que também influenciaram o IAF, IL e densidade populacional de perfilhos, que alterou as taxas de acúmulo de forragem. Segundo Gomide et al. (2003), outros fatores contribuem para a falta de consistência da relação entre IL, IAF e taxa de acúmulo de matéria seca, uma vez que plantas interagem dinamicamente com outros componentes além do ambiente.

A redução na taxa de acúmulo de forragem observada a partir do outono é decorrente do início do período seco, no qual a ocorrência de condições adversas pode ter levado a diminuição da emissão de novas folhas, cessamento do alongamento e expansão de folhas, o que pode inibir, ainda, reduzir e, ou, impedir o aparecimento de novos perfilhos. Em última instância, essas alterações acarretam redução na produção do pasto (SBRISSIA et al.,
2001). Portanto, as variações nas condições climáticas, ocorridas no ano de 2008, sugerem alterações na arquitetura das plantas e do dossel, nas características morfofisiológicas da pastagem relacionadas com época do ano e adubação nitrogenada. Portanto, são necessários mais estudos com a finalidade de propiciar o entendimento dos padrões de resposta e estabelecer relações causa-efeito, de forma que parâmetros-guia de manejo do pastejo possam ser estabelecidos clara e objetivamente, no intuito de assegurar a produtividade e longevidade das pastagens cultivadas.

Os pastos de Cynodon cv. Tifton 85 sofrem influência da época de avaliação e das doses de nitrogênio com efeito marcante no material morto do pasto, índice de área foliar, interceptação luminosa e densidade de perfilhos basilares, que são determinantes no acúmulo de forragem. O cultivar Tifton 85 não atingiu as condições necessárias para a taxa de crescimento da cultura 
Rev. Bras. Saúde Prod. Anim., Salvador, v.13, n.2, p.306-317 abr./jun., 2012 http://www.rbspa.ufba.br ISSN 15199940

máxima, quando manejado sob lotação contínua mantendo-se o pasto a $10 \mathrm{~cm}$ de altura.

\section{REFERÊNCIAS}

ALENCAR, C.A.B.; OLIVEIRA, R.A.; CÓSER, A.C.; MARTINS, C.E.; FIGUEIREDO, J.L.A.; CUNHA, F.F.; CECON, P.R.; LEAL, B.G. Produção de seis capins manejados por pastejo sob efeito de diferentes doses nitrogenadas e estações anuais. Revista Brasileira de Saúde e Produção Animal, v.11, n.1, p.48-58, 2010.

ALEXANDRINO, E.; NASCIMENTO JÚNIOR, D.; MOSQUIM, P.R.; REGAZZI, A.J.; ROCHA, F.C. Características morfogênicas e estruturais na rebrotação da Brachiaria brizantha cv. Marandu submetida a três doses de nitrogênio. Revista Brasileira de Zootecnia, v.33, n.6, p.1372-1379, 2004.

ANDRADE, C.M.S.; GARCIA, R.; VALENTIM, J.F.; PEREIRA, O.G. Grazing management strategies for massaigrass-forage peanut pastures: 1 . Dynamics of sward condition and botanical composition. Revista Brasileira de Zootecnia, v.35, n.2, p.334 - 342, 2006.

BARBERO, L.M.; CECATO, U.; LUGÃO, S.M.B.; GOMES, J.A.N.; LIMÃO, V.A.; BASSO, K.C. Produção de forragem e componentes morfológicos em pastagem de coastcross consorciada com amendoim forrageiro. Revista Brasileira de Zootecnia, v.38, n.5, p.788-795, 2009.
CARNEVALLI, R.A.; SILVA, S.C. Validação de técnicas experimentais para avaliação de características agronômicas e ecológicas de pastagens de Cynodon dactylon cv. Coastcross-1. Scientia Agricola, v.56, n.2, p.489-499, 1999.

CARNEVALLI, R.A.; DA SILVA, S.C.; FAGUNDES, J.L.; SBRISSIA, A.F.; CARVALHO, C.A.B.; PINTO, L.F.M.; PEDREIRA, C.G.S. Desempenho de ovinos e respostas de pastagens de Tifton 85 (Cynodon spp.) sob lotação contínua. Scientia Agricola, v.58, n.1, p.7-15, 2001.

CARVALHO, C.A.B.; SILVA, S.C; SBRISSIA, A.F.; PINTO, L.F.M.; CARNEVALLI, R.A.; FAGUNDES, J.L; PEDREIRA, C.G.S. Demografia do perfilhamento e taxas de acúmulo de matéria seca em capim Tifton 85 sob pastejo. Scientia Agricola, v.57, n.4, p.591-600, 2000.

DAVIES, A. Tissue turnover in the sward. In: DAVIS, A; BAKER, R.D.; GRANT, S.A.; LAIDLAW, A.S. (Eds.). Sward Measurement Handbook. 2.ed. England: The British Grassland Society/ University of Reading: Reading, 1993. p.183-216.

ESTRADA, A.D.; CARVALHO, S.R.; ALMEIDA, J.C.C.; CAMARGO FILHO, S.T. Influência do intervalo de corte sobre a produção de matéria seca e o teor de nitrogênio em gramíneas dos gêneros Cynodon e Digitaria. Revista

Universidade Rural, v.23, n.2, p.192 26, 2003.

FAGUNDES, J.L.; FONSECA, D.M.; GOMIDE, J.A.; NASCIMENTO JR, D.; VITOR, C.M.T.; MORAIS, R.V.; MISTURA, C.; REIS, G.C.; MARTUSCELLO, J.A. Acúmulo de forragem em pastos de Brachiaria decumbens adubados com nitrogênio.

Pesquisa Agropecuária Brasileira, v.40, n.4, p.397-403, 2005. 
Rev. Bras. Saúde Prod. Anim., Salvador, v.13, n.2, p.306-317 abr./jun., 2012 http://www.rbspa.ufba.br ISSN 15199940

FAGUNDES, J.L.; FONSECA, D.M.; MISTURA, C.; MORAIS, R.V.; VITOR, C.M.T.; GOMIDE, J.A.; NASCIMENTO JÚNIOR, D.; CASAGRANDE, D.R.; COSTA, L.T. Características morfogênicas e estruturais do capimbraquiária em pastagem adubada com nitrogênio avaliadas nas quatro estações do ano. Revista Brasileira de Zootecnia, v.35, n.1, p.21-29, 2006 a.

FAGUNDES, J.L.; FONSECA, D.M.; MORAIS, R.V.; MISTURA, C.; VITOR, C.M.T.; GOMIDE, J.A.; NASCIMENTO JÚNIOR, D.; SANTOS, M.E.R.; LAMBERTUCCI, D.M. Avaliação das características estruturais do capimbraquiária em pastagens adubadas com nitrogênio nas quatro estações do ano.

Revista Brasileira de Zootecnia, v.35, n.1, p.30-37, 2006b.

FAGUNDES, J.L.; SILVA, S.C.; PEDREIRA, C.G.S.; CARNEVALLI, R.A.; CARVALHO, C.A.B.; SBRISSIA, A.F.; PINTO, L.F.M. Índice de área foliar, coeficiente de extinção luminosa e acúmulo de forragem em pastagens de Cynodon ssp. sob lotação contínua.

Pesquisa Agropecuária Brasileira, v.36, n.1, p.187-195, 2001.

GOMIDE, C.A.M.; GOMIDE, J.A.; ALEXANDRINO, E. Índices morfogênicos e de crescimento durante o estabelecimento e rebrotação do capim-Mombaça ( $P$. maximum).

Revista Brasileira de Zootecnia, v.32, n.4, p.795-803, 2003.
MORAIS, R.V.; FONSECA, D.M.; MOREIRA, L.M.; NASCIMENTO JÚNIOR, D.; RIBEIRO JÚNIOR, J.I.; FAGUNDES, L.J.; MISTURA, C.; MARTUSCELLO, J.A. Demografia de perfilhos basilares em pastagem de Brachiaria decumbens adubada com nitrogênio. Revista Brasileira de Zootecnia, v.35, n.2, p.380- 88, 2006.

PACIULLO, D.S.C.; AROEIRA, L.J.M.; MORENZ, M.J.F.; HEINEMANN, A.B. Morfogênese, características estruturais e acúmulo de forragem em pastagem de Cynodon dactylon, em diferentes estações do ano. Ciência Animal Brasileira, v.6, n.4, p.233-241, 2005.

SANTOS, M.E.R.; FONSECA, D.M.; BALBINO, E.M.; MONNERAT, J.P.I.S.; SILVA, S.P. Caracterização dos perfilhos em pastos de capimbraquiária diferidos e adubados com nitrogênio. Revista Brasileira de Zootecnia, v.38, n.4, p.643-649, 2009.

SAS INSTITUTE. SAS/STAT: user's guide. Version 9.1.3. Cary, 2004.

SBRISSIA, A.F.; SILVA, S.C.; CARVALHO, C.A.B.; CARNEVALLI, R.A.; PINTO, L.F.M.; FAGUNDES, J.L.; PEDREIRA, C.G.S. Tiller size/population density compensation in grazed Coastcross bermudagrass swards. Scientia Agricola, v.58, n.4, p.655-665, 2001.

Data de recebimento: $25 / 05 / 2011$

Data de aprovação: 24/04/2012 